\title{
On the use of Sentinel-2 for coastal habitat mapping and satellite-derived bathymetry estimation using downscaled coastal aerosol band
}

\author{
Dimitris Poursanidis $^{\mathrm{a}, *}$, Dimosthenis Traganos ${ }^{\mathrm{b}}$, Peter Reinartz ${ }^{\mathrm{c}}$, Nektarios Chrysoulakis ${ }^{\mathrm{a}}$ \\ ${ }^{a}$ Foundation for Research and Technology - Hellas, Institute of Applied and Computational Mathematics, rslab.gr, Greece \\ ${ }^{\mathrm{b}}$ German Aerospace Center (DLR), Remote Sensing Technology Institute, Rutherfordstraße 2, 12489 Berlin, Germany \\ ${ }^{\mathrm{c}}$ German Aerospace Center (DLR), Earth Observation Center (EOC), 82234 Weßling, Germany
}

\section{A R T I C L E I N F O}

\section{Keywords:}

Posidonia oceanica

Seagrass

Coastal habitat mapping

Satellite-derived bathymetry

Sentinel-2

Super-resolution

\begin{abstract}
A B S T R A C T
Coastal habitats provide a plethora of ecosystem services, yet they undergo continuous pressure and degradation due to the human-induced climate change. Conservation and management imply continuous monitoring and mapping of their spatial distribution at first. The present study explores the capabilities of the Copernicus Sentinel-2 mission and the contribution of its coastal aerosol band $1(443 \mathrm{~nm})$ for the mapping of the dominant Mediterranean coastal marine habitats and the bathymetry in three survey sites in the East Mediterranean. The selected sites have shallow to deep habitats and a high variability of oceanographic and seabed morphological conditions. The major findings of our study demonstrate the advantages of the downscaled Sentinel-2 coastal aerosol band 1 for both optically shallow habitat and satellite-derived bathymetry mapping due to its great water penetration. The use of Sentinel-2 band 1 allows detection of Posidonia oceanica seagrass beds down to $32.2 \mathrm{~m}$ of depth. Sentinel-2 constellation with its 10-m spatial resolution at most of the spectral bands, 5-day revisit frequency and open data policy can be an important tool to provide crucial missing information on the spatial distribution of coastal habitats and on their bathymetry distribution, especially in data-poor and/or remote areas with large gaps in a retrospective, rapid and non-intrusive manner. As such, it becomes a crucial ally for the conservation and management of coastal habitats globally.
\end{abstract}

\section{Introduction}

Marine plants form seagrass meadows which constitute the foundation of the biodiversity and human well-being. These provide several ecosystem services such as carbon sequestration, nursery and feeding grounds for fisheries, coastal protection from erosion, and hotspot of biodiversity (Cullen-Unsworth and Unsworth, 2013; Vassallo et al., 2013). However, according to Waycott et al. (2009), seagrass beds have lost $29 \%$ of their global extent since 1879 . This implies that almost $1 / 3$ of the provided ecosystem services has already been lost. Engineered by the endemic Posidonia oceanica between 0-40 m, the Mediterranean meadows form the basis for a key marine habitat/ecosystem in the region (Boudouresque et al., 2012). Knowledge of their spatial distribution is an important prerequisite information towards the proper management of habitats (Levin et al., 2014). Several mapping programs have focused on coastal seabed mapping while a wide range of methods has been utilized for mapping seagrasses (Borfecchia et al., 2013; Eugenio et al., 2015; Hamana and Komatsu, 2016; Hossain et al., 2014; Sagawa et al., 2010; Traganos et al., 2018b). Satellite remote sensing has been employed for the mapping of seagrass meadows and coral reefs in several areas (Goodman et al., 2013; Hedley et al., 2016; Knudby and Nordlund, 2011; Koedsin et al., 2016; Lyons et al., 2012). The present study evaluates the quality of the Copernicus Sentinel-2 (S2) mission for mapping the major Mediterranean coastal marine habitats with focus on the dominant $P$. oceanica seagrass and bathymetry in three survey sites in the south Aegean Sea. The selected sites, Marathon Schinias National Park, Samaria National Park and Gavdos Island, include shallow to deep habitats and a highly variable oceanographic and seabed morphology, allowing the development and testing of a comprehensive pre-processing procedure. The procedure uses a combination of empirical image-based, semi-analytical and analytical methods, including the downscaling of the coarser resolution S2 bands to $10 \mathrm{~m}$, sunglint correction, ratio-based satellite-derived bathymetry, depth-invariant indices and analytical water column correction. Integral in the current study is the downscaling approach of the coastal aerosol band 1 (443 nm; Brodu, 2017) which due to its great water penetration is expected to benefit the coastal habitat mapping (CHM) and satellite-derived bathymetry (SDB) in an extreme bathymetric range for spaceborne approaches.

\footnotetext{
* Corresponding author.

E-mail address: dpoursanidis@iacm.forth.gr (D. Poursanidis).
} 


\section{Materials and methods}

\subsection{Study areas}

The selected sites are in water bodies with different oceanographic and topographic characteristics (SoHelME, 2005). This variety allows comparisons for the capabilities of Sentinel-2 in seabed mapping in areas with medium and low productivities. The National Park of Marathon-Schinias (hereafter Schinias) covers a landscape of $56 \mathrm{~km}^{2}$ in the marine body of the Petalioi Gulf, at the outlay of the South Evoikos Gulf. The studied area is the coastal zone of the park where seagrass meadows are present between 2 and $20 \mathrm{~m}$ (Fig. 1a). Samaria National Park (hereafter Samaria) is located in the West part of the island of Crete; it was declared as a National Park in 1962. The selected area lies

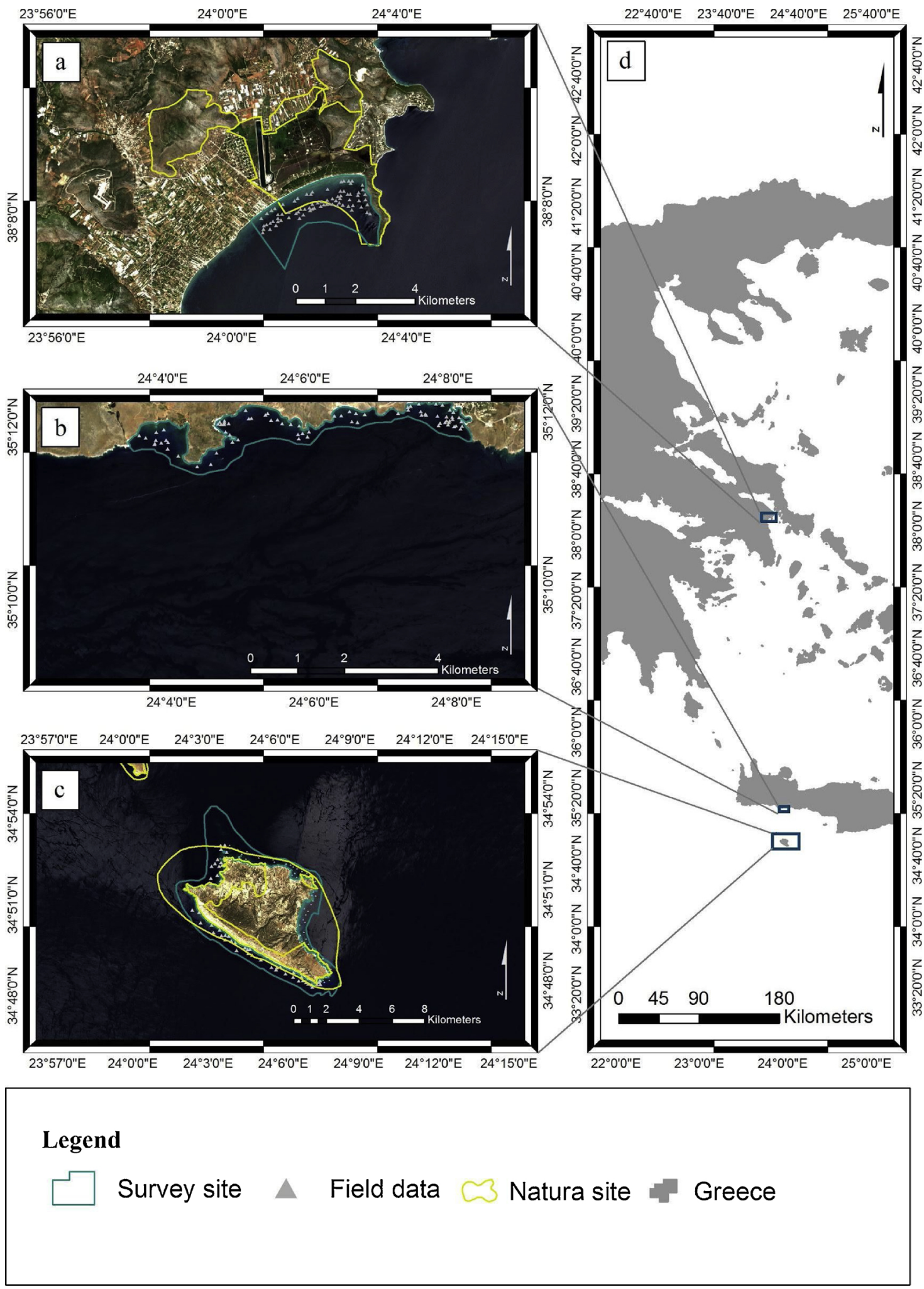

Fig. 1. Location of survey site in (a) Schinias Marathon National Park, (b) Samaria National Park, (c) Gavdos Island, and (d) Greece. 
Table 1

Characteristics of Sentinel-2 A images.

\begin{tabular}{lll}
\hline Survey site & Schinias & Samaria \& Gavdos \\
\hline Granule & 34 SGH & 34 SGD \\
Acquisition date & 15 June 2017 & 26 April 2017 \\
Acquisition time & $09: 05$ am UTC & $09: 10$ am UTC \\
Mean solar zenith angle & $20.4^{\circ}$ & $25.3^{\circ}$ \\
Mean solar azimuth angle & $132.6^{\circ}$ & $142.7^{\circ}$ \\
\hline
\end{tabular}

up to $38 \mathrm{~m}$ deep and features mainly patchy seagrasses (Fig. 1b). Gavdos island (hereafter Gavdos) is in the southernmost point of Europe and Greece. The studied area concerns the coastal part of the island where seagrass meadows thrive between 5 and $25 \mathrm{~m}$ of depth (Fig. 1c)

\subsection{Sentinel-2 data}

Copernicus Sentinel-2 A (S2-A) L2A satellite data from the first of the two polar-orbiting satellites, have been selected and downloaded from the Sentinel Scientific Data Hub for the present study (ESA, 2015). L2A data have been corrected from L1C using the rural (continental) aerosol type, a mid-latitude summer atmospheric profile, a value of 331 Dobson Units for ozone concentration, a land-average value for water vapor over water, a visibility of $40 \mathrm{~km}$ and an adjacency range of $1 \mathrm{~km}$. Here, we have processed and analyzed two S2-A images (Table 1); one for Schinias, and one for Samaria and Gavdos, as one S2 tile covers both areas.

\subsection{In situ data}

Field data for the three distinctive Mediterranean coastal habitats in the selected three sites (Fig. 2) have been collected with various approaches. These are: a) P. oceanica seagrass meadows (Fig. 2a, c); b) rocky bottoms covered by photophilous algae (Fig. 2b); c) soft/sandy bottoms (Fig. 2d). For the sites located in Crete, we collected the data in summer 2013 during research activities for the ecological status of the seagrass meadows (Poursanidis et al., 2014) in Samaria and Gavdos Natura 2000 site, and updated them in summer 2017.

We collected the data by snorkeling between $0-5 \mathrm{~m}$ and SCUBA diving between 5-45 m. In both cases, the field scientist used a waterproof GPS unit (GARMIN GPSMAP series) either on a buoy or on hand and collected the data. In each site (Samaria and Gavdos), we acquired 20 POIs per habitat for use in image classification. Bathymetric data were collected only in Samaria by using a Lowrance HDS5 gen2 with a single beam sonar head placed $15 \mathrm{~cm}$ below the water surface. We collected 107 field points in total in Gavdos and 79 field points in Samaria. In the case of Schinias, we extracted 64 field points by interpreting high-resolution aerial images by the National Cadaster \& Mapping Agency S.A. from 2010 and open access high resolution images between 2010-2016 in Google Earth.

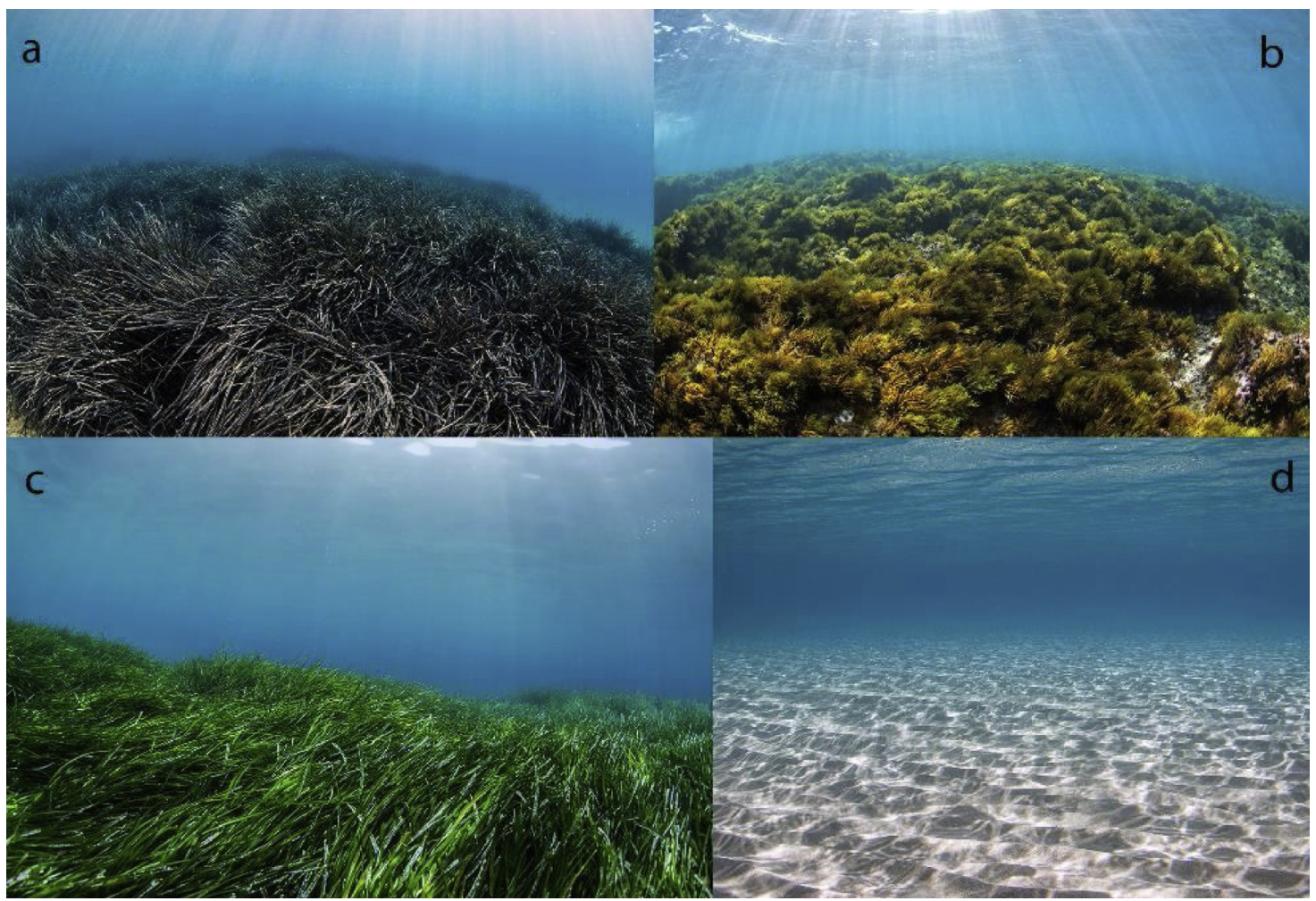

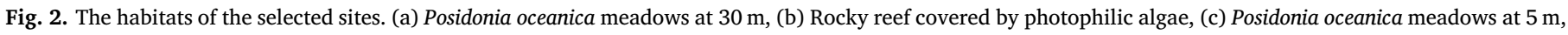
and (d) Soft sandy bottom. 


\subsection{Pre-processing steps}

Fig. 3 provides an overview of the designed methodology for the processing and classification of S2-A images. As a panchromatic band is absent in Sentinel-2, a different approach than pan-sharpening is needed to increase the spatial and spectral information of the coastal aerosol band $1(443 \mathrm{~nm})$. Band 1 is of significant importance in the remote sensing of coastal waters (Mouw et al., 2015) due to its deeper penetration than the other visible bands. Brodu (2017) developed a downscaling method, namely super-resolution, for multispectral, multiresolution imagery as the Sentinel-2 satellites. We run the downscaling algorithm using the Sen2Res plugin in ESA'S Sentinel Application Platform (SNAP) Version 5.0 for all survey sites (Fig. 4) in order to downscale all spectral bands at $10 \mathrm{~m}$. We use the downscaled Shortwave Infrared SWIR band 11 at $1610 \mathrm{~nm}$ to mask all terrestrial features in all survey sites by classifying the image into water and land with an Iso Cluster Unsupervised Classification. We correct sunglint using the method of Hedley et al. (2005). We also implement the Lyzenga depthinvariant indices (DIV) (Lyzenga, 1978, 1981) to empirically address the influence of variable depth on optically shallow seabed. We estimate three DIV (b1-b2, b2-b3, b1-b3) for all three survey sites.

\subsection{Analytical water column correction - Bathymetry estimation}

In contrast to the empirical image-based technique of Lyzenga (1978, 1981), semi-analytical and analytical water column corrections are expected to increase classification accuracies by minimizing the water column interference on the signal of the submerged habitats in a more efficient manner. We implement the analytical water column correction model of Maritorena et al. (1994), while for the bathymetry estimation we employ the ratio method of Stumpf et al. (2003).

\subsection{Classifications and uncertainty estimation}

We utilize the machine learning classifiers of Support Vector Machines (SVM) and Random Forests (RF) - widely used in the remote sensing of optically shallow habitats (Eugenio et al., 2015; Traganos and Reinartz, 2017a, 2017b; Zhang, 2015). We employ both classifiers on all types of reflectance composites - the first three Sentinel-2 A bands in 10-m resolution (bands 1-3) in all three survey sites: a) Atmospherically corrected L2A imagery $(R)$; b) deglinted L2A imagery $\left(R^{\prime}\right)$; c) DIV; d) substrate remote sensing reflectance composites $\left(R \mathrm{rs}^{b}\right)$ in the case of Samaria. SVM are a group of universal machine learning algorithms based on the statistical learning theory of Vapnik (1995), while $\mathrm{RF}$ comprise an ensemble method for supervised classification based on classification and regression trees (CART) and were developed by Breiman (2001). To increase understanding as well as interpretation of our classification results, we decided to output them as class probability estimates (soft classification) instead of the typical multi-class hard classification outputs. To estimate per pixel probabilities, binary RFand SVM-derived decision values are first transformed into binary probabilities according to Platt (2000) and then into class probabilities following the pair-wise coupling approach (one-against-one) of $\mathrm{Wu}$ et al. (2004). All experiments with SVM/RF and probability estimates

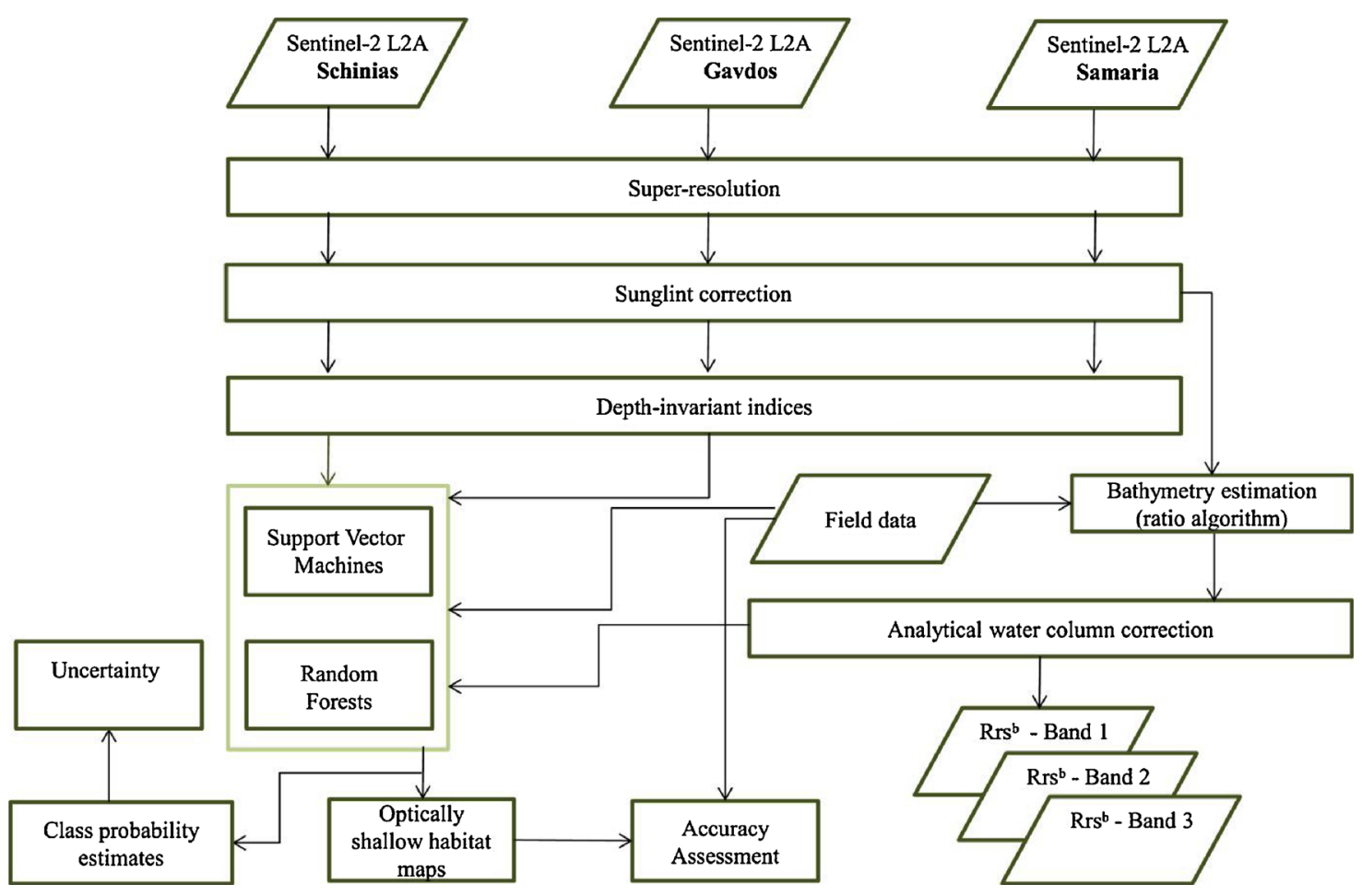

Fig. 3. Schematic methodological workflow. 
were run in EnMAP-Box (van der Linden et al., 2015). We utilise Shannon entropy $(H)$ (Shannon, 1948) to output per-pixel uncertainty as a function of class probabilities. We evaluate the hard classification results (the coastal habitat maps) by calculating overall (OA), producer (PA) and user accuracy (UA) of every class per survey site.

\section{Results}

\subsection{Pre-processing results}

Fig. 4 displays Sentinel-2 A L2A 4-3-2 composites from our three survey sites along with the coastal aerosol band ( $443 \mathrm{~nm}$ ) over each site in its initial and super-resolved resolution (60 and 10-m correspondingly). The pink and yellow polygons in 4(e) and (f) display selected super-resolved pixels (sandy and rocky seabed) with same reflectance as the initial 60-m initial pixel - 00,489 $\pm 00,009$ (rocks) and $00,629 \pm 0003$ (sands) - demonstrating that super-resolution preprocessing does not impact the sensor radiometry. Deglinted L2A 3-2-1 composites are depicted in Fig. 5. Especially in the Schinias (Figs. 5a, b) and Gavdos (Figs. 5e, f, g, h), benthic features were spectrally enhanced following the sunglint correction of Hedley et al. (2005). Fig. 6 shows the image-based DIV (Lyzenga, 1978, 1981) in all three field sites. Light

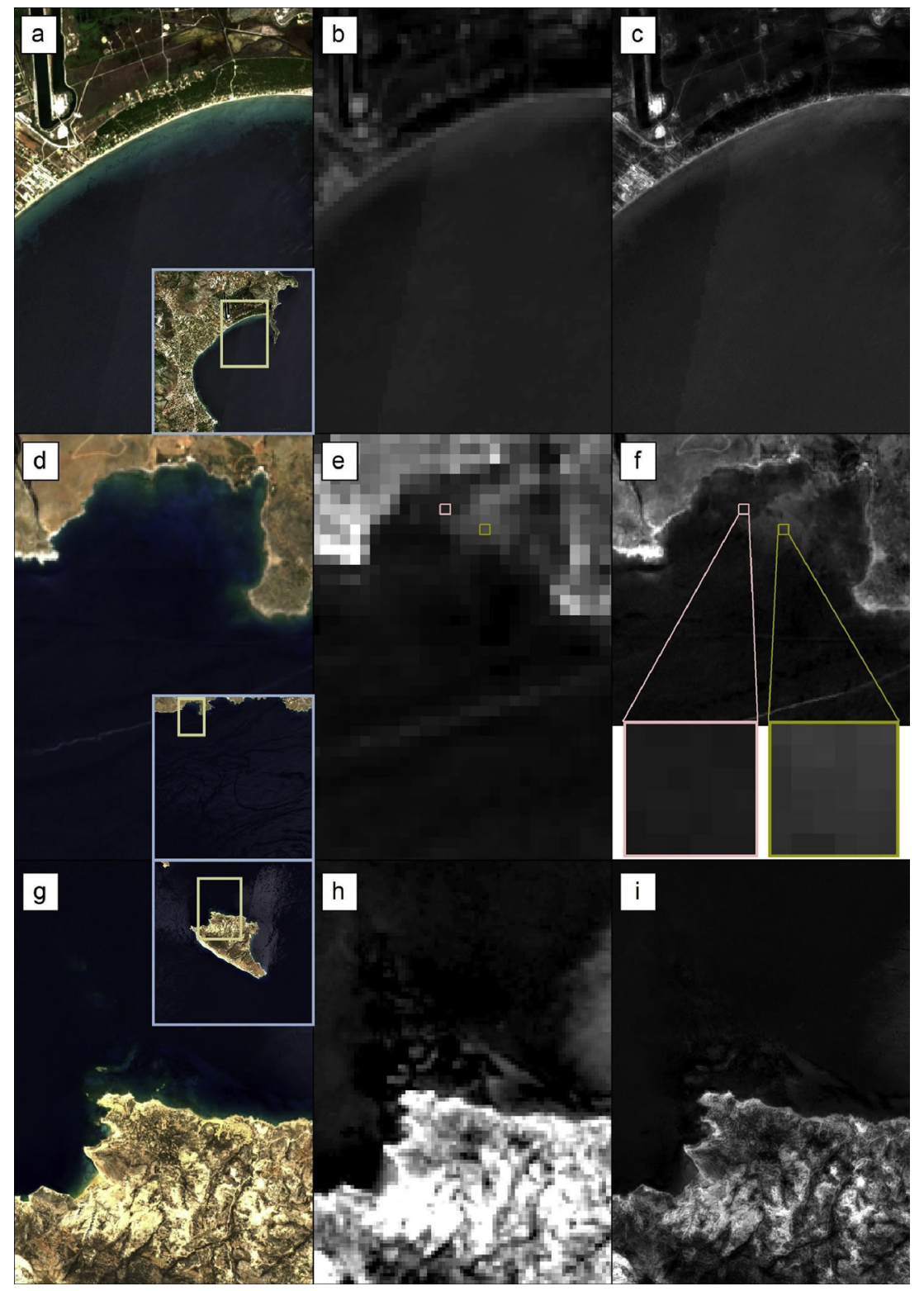

Fig. 4. Downscaling of Sentinel-2 band 1 following Brodu (2017). (a), (d), (g): 4-3-2 composite images of Schinias, Samaria, and Gavdos Island. (b), (e), (h): Original band $1(443 \mathrm{~nm}, 60-\mathrm{m}$ resolution). (c), (f), (i): Downscaled band 1 at 10-m resolution. The pink and yellow squares in Fig. 4(f) show the downscaled 10-m pixels over a rocky and sandy seabed, respectively. The polygon in the three insets of 4(a), (d) and (g) indicates the location of the displayed panels within the extent of each survey site (For interpretation of the references to colour in this figure legend, the reader is referred to the web version of this article). 


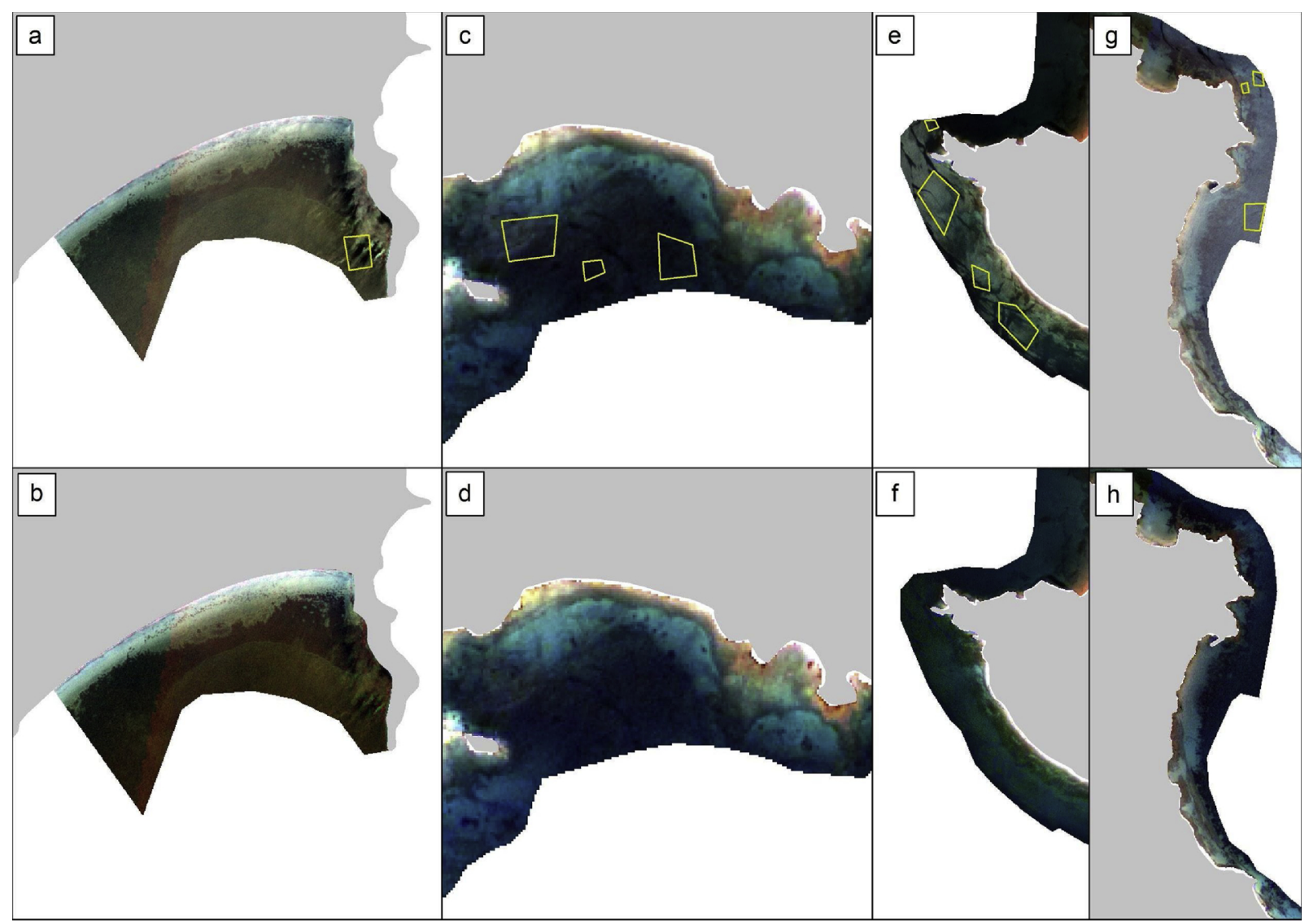

Fig. 5. Sunglint correction of Sentinel-2 A images following Hedley et al. (2005). All images are 3-2-1 L2A composites with downscaled band 1 at 10-m resolution. Yellow polygons indicate pixels selected for the regression. (a), (b): Initial and deglinted image of Schinias. (c), (d): Initial and deglinted image of the centre of Samaria. (e), (g), (f), (h): Initial and deglinted images of NW and E Gavdos (For interpretation of the references to colour in this figure legend, the reader is referred to the web version of this article).

blue polygons in the insets of Fig. 6 indicate pixel areas of sandy substrate used in the estimation of the indices. Negative DIV values were observed and were corrected to cover positive ranges, incorporating an offset. Essential to both the estimation of accurate depth-invariant indices as well as to the analytical water column correction, the ratios of diffuse attenuation coefficient $k_{1} / k_{2}, k_{2} / k_{3}$, and $k_{1} / k_{3}$ were estimated as $0.64,0.53$, and 0.33 for Schinias; $0.77,0.53$, and 0.37 for Samaria; $1.18,0.28$, and 0.05 for Gavdos.

\subsection{Analytical water column correction and bathymetry estimation}

Available field depth data allowed the estimation of substrate remote sensing reflectances $\left(\mathrm{Rrs}^{b}\right)$ (Fig. 7a). Wavelength-dependent attenuation coefficients $(k)$ of the Sentinel-2 b1, b2 and b3 bands in Samaria were estimated as $0.03 \mathrm{~m}^{-1}, 0.04 \mathrm{~m}^{-1}$ and $0.08 \mathrm{~m}^{-1}$. These values were incorporated in Equation (3) to derive $R r s^{b}$ (S1 file). Furthermore, utilising $k$, we estimated the 'effective penetration depth' (EPD) in the first three visible bands; $74 \mathrm{~m}$ in $443 \mathrm{~nm}, 57.5 \mathrm{~m}$ in
$490 \mathrm{~nm}$, and $30.2 \mathrm{~m}$ in $560 \mathrm{~nm}$. Employing Equations (5) and (6) (S1 file), we produced a $10-\mathrm{m}$ bathymetry $(Z)$ map of the Samaria site (Fig. 8). The implemented ratio of Equation 6 (S1 file) exploited the different attenuation of the b1 and b3 to retrieve water depths. Additionally, we derived a second bathymetry map (not shown here), utilising Equation (7) and (8) (S1 file), where we used the ratio of the b2 to b3 band. The validation of both SDBs was assessed with 1658 in situ depth measurements from the total of 2569 (Fig. 9a). Linear regressions between SDBs and field measurements revealed a superior $r$ squared value of 0.85 and a smaller root-mean-square error (RMSE) of $4.31 \mathrm{~m}$ following use of the b1-b3 ratio (Fig. 9) in comparison to the rsquared value of 0.68 and the RMSE of $5.46 \mathrm{~m}$ of the b2-b3 ratio. Blending knowledge of the bathymetry and effective penetration depth of Sentinel-2 imagery, we masked waters below $30.2 \mathrm{~m}$ (Figs. 7a). Past the EPD in $560 \mathrm{~nm}$, the analytical water correction model might be possibly compromised or not be able to correct the depth effect $\left(\mathrm{e}^{-2 k \mathrm{z}}\right)$ in Equation (3) ( $\mathrm{S} 1$ file). We also masked waters below $43 \mathrm{~m}$ following the findings of Poursanidis et al. (2018) which show that the deep limit of $P$. oceanica seagrass lies on this depth. 


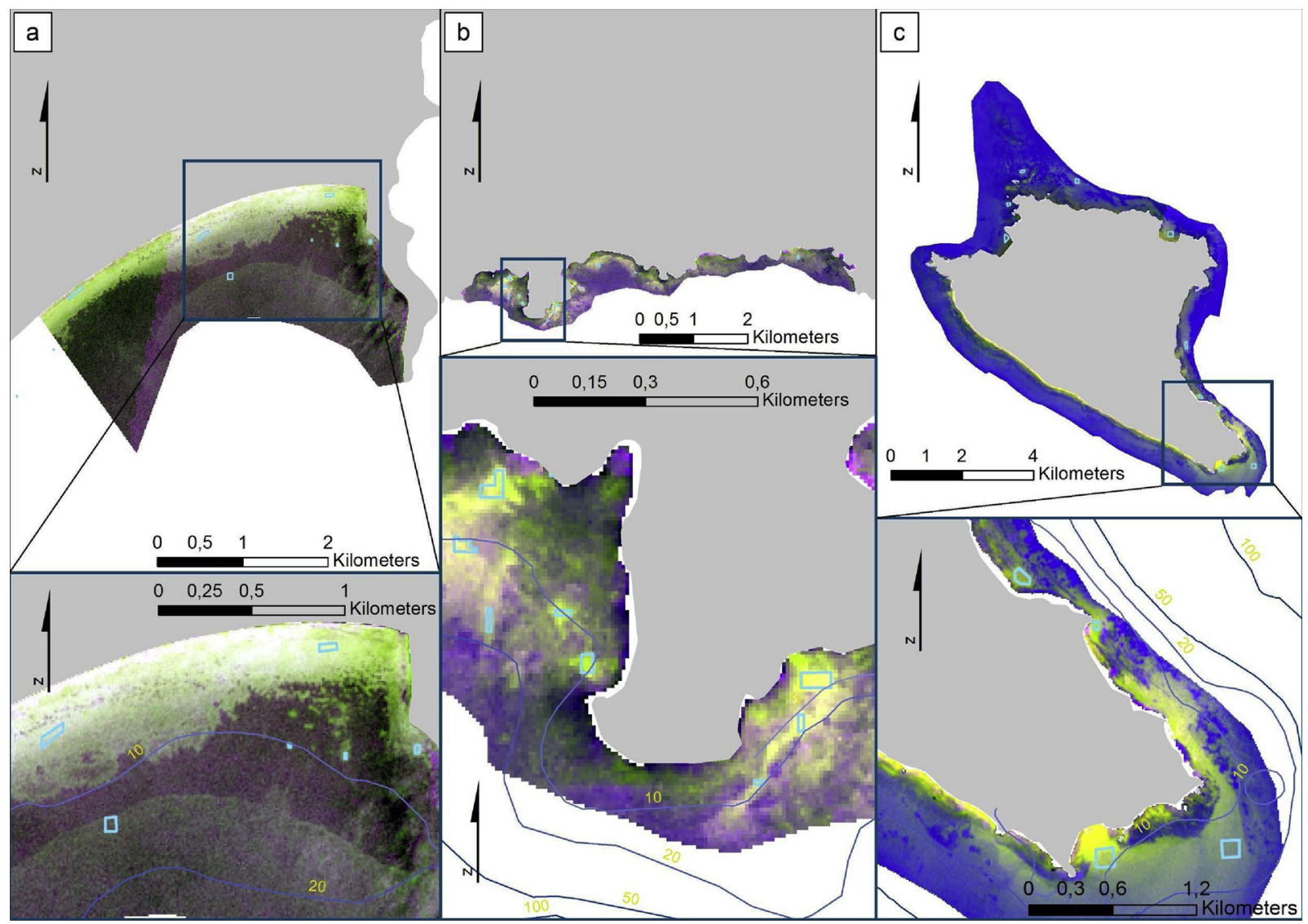

Fig. 6. Depth-invariant bottom indices (b1-b2, b1-b3 and b2-b3) following Lyzenga $(1978,1981)$. Light blue polygons indicate regression pixels that represent the same substrate, sand, in different depths. (a) Schinias, (b) Samaria, (c) Gavdos (For interpretation of the references to colour in this figure legend, the reader is referred to the web version of this article).

\subsection{Classifications and uncertainty estimation}

Two machine learning classifiers, SVM and RF, were applied to three different composites in three survey sites for a total of 24 classified habitat maps. Except from the case of $\operatorname{Rrs}^{b}$ composites in the Samaria site, the other classified composites were the S2-A L2A, the deglinted L2A and the DIV. In Samaria, P. oceanica seagrass occupy depths up to $32.2 \mathrm{~m}$ in the eastern part of this site with a $96.8 \%$ probability and $14.7 \%$ uncertainty as revealed by the SVM-classified full-depth $\operatorname{Rrs}^{b}$ composite (OA: 75\%, PA: 100\%, UA: 72.5\%) and SDB (Fig. 8). Generally, SVM exhibited a marginal higher overall accuracy on classifying the L2A and deglinted L2A composites $(+2.5 \%)$ than the $\mathrm{Rrs}^{b}$ imagery. In addition, the highest uncertainties are depicted in deeper areas $(>20 \mathrm{~m})$ which are immersed in noise (Fig. 7e).

In Schinias, the SVM-classified deglinted L2A composite (Fig. 12a) yielded the best OA of $87.2 \%$ (S2 file). This classified composite featured similar PA of seagrasses (82.6\%) to the SVM L2A and RF L2A composites. On the other hand, the RF-classified DIV composite was the most accurate product in both PA and UA. Classifier-wise, SVM were slightly more accurate than Random Forests in the two-class experiments here, exhibiting $0.9 \%$ better OA. They also displayed $2.9 \%$ greater PA but $1 \%$ lower UA in classifying seagrass. Fig. $11 \mathrm{~d}$ indicates a lower uncertainty in areas shallower than $10 \mathrm{~m}$.

In Gavdos, the RF-derived deglinted L2A imagery (Fig. 11a) showed the greatest OA $(58.2 \%)$ in classifying the benthic habitats of the island (S2 file). More particularly, as regards to the class of $P$. oceanica and overall classifier performance, RF featured a $10.9 \%$ better OA than SVM, a $2.7 \%$ lower PA and a greater UA of $13.6 \%$. P. oceanica class probability seems to be overestimated over optically deep areas (Fig. 12b), while uncertainty measure reveals a higher certainty on the eastern and southern part of Gavdos Island in contrast to its western part (Fig. 12e). While SVM exhibited a marginal difference from RF in OA by $2.7 \%$, it demonstrated noteworthy greater PA and UA of $P$. oceanica seagrass class of $25.9 \%$ and $21.1 \%$.

\section{Discussion}

The present study selected three protected, eastern Mediterranean sites to evaluate the potential of the Sentinel-2 sensor in coastal habitat mapping and satellite-derived bathymetry over a variety of seabed 


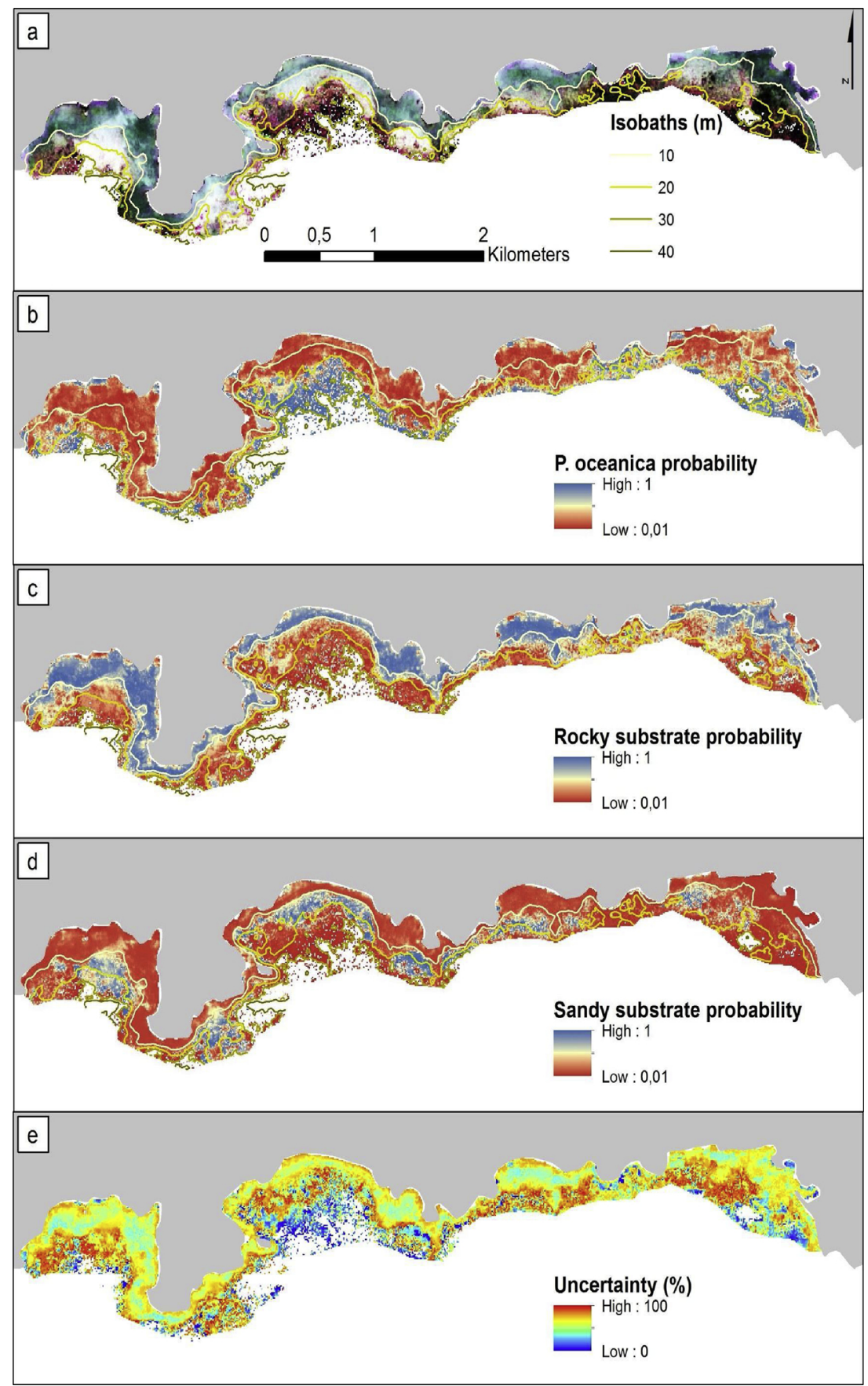

Fig. 7. Water column corrected S2-A 3-2-1 composite of Samaria survey site, and related probability and uncertainty of habitat distribution. Isobaths are based on a $5 \times 5$ smoothing of the SDB. (a) Substrate remote sensing reflectance $\left(R \mathrm{rs}^{b}\right)$ image up to $30.2 \mathrm{~m}$ of depth. (b), (c), (d) SVM-derived probability of $P$. oceanica, rocky and sandy substrate (\%), respectively.

morphologies and oceanographic characteristics. The coastal aerosol band 1 of $S 2$ in $443 \mathrm{~nm}$ is the common denominator in the two major findings of our study. Leveraging empirical to analytical corrections and machine, we first found that $\mathrm{S} 2$ can detect $P$. oceanica seagrasses 32.2-m deep into the South Cretan water column (Fig. 10). We mainly attribute this finding to the high oligotrophic Cretan Sea which features a very low primary production (Psarra et al., 2000) and a strong pelagic microbial loop which subsequently reduces particle flux to the sediment 


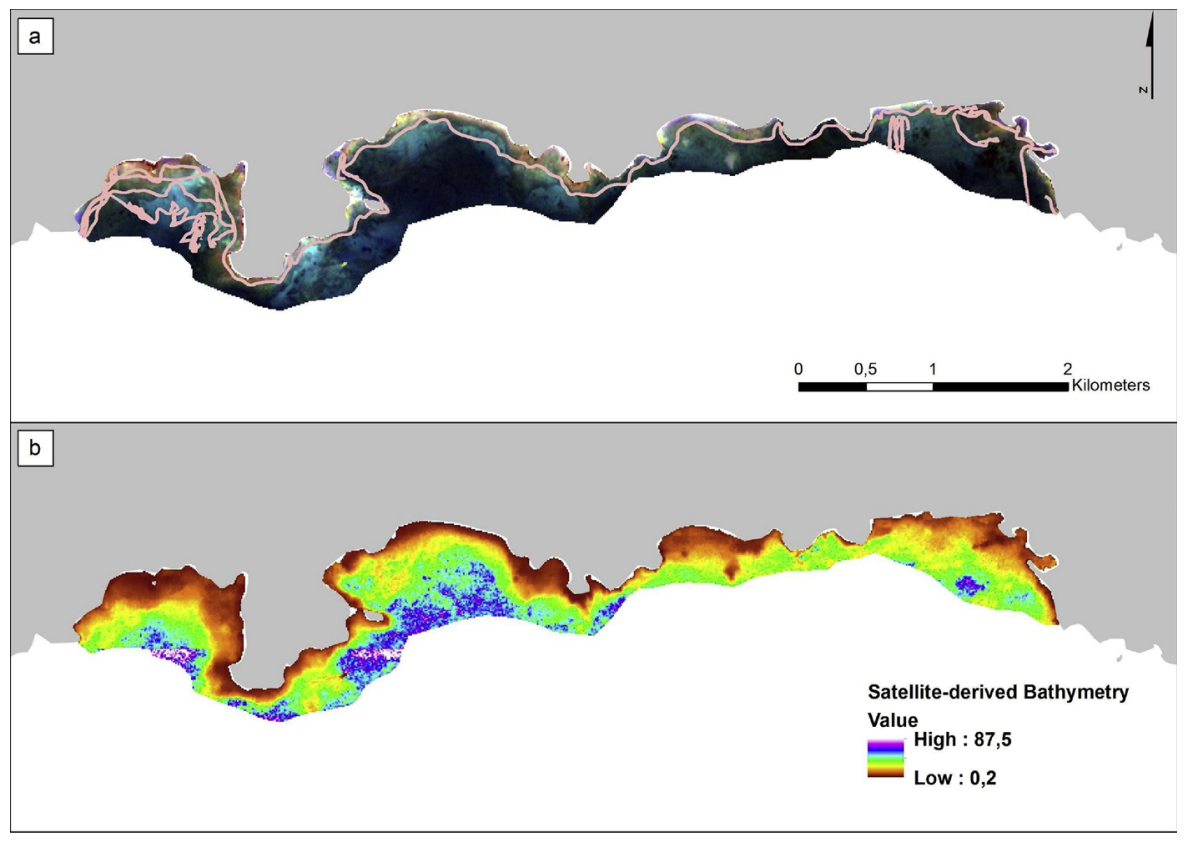

Fig. 8. Satellite-derived bathymetry (SDB) of the Samaria survey site based on the ratio of coastal aerosol to green band. (a) Deglinted L2A 3-2-1 composite of the survey site. In situ depth data $(\mathrm{n}=2569)$ are shown in light pink. (b) SDB for the whole depth range (For interpretation of the references to colour in this figure legend, the reader is referred to the web version of this article).

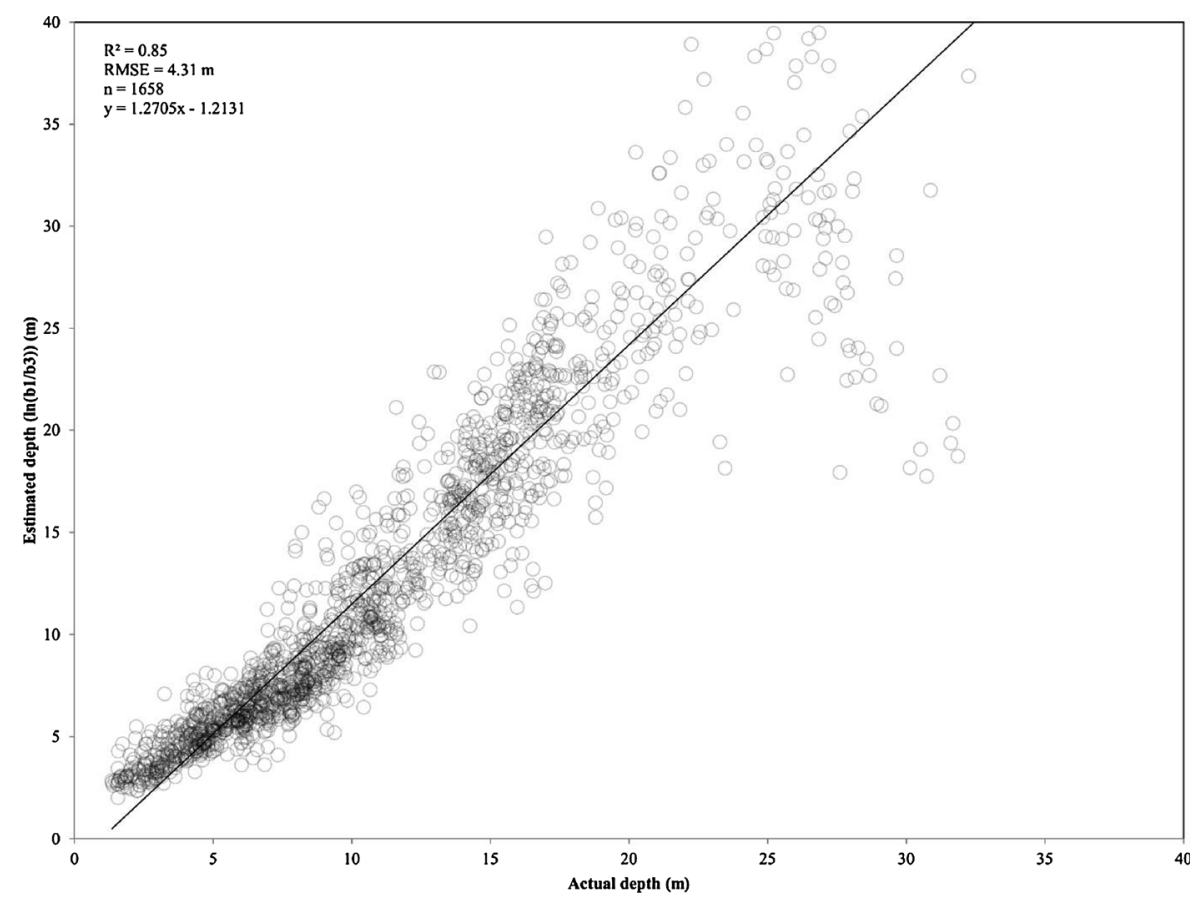

Fig. 9. Linear regression between SDB using the b1-b3 ratio and actual depth measurements from the Samaria site. The SDB was implemented in the analytical water column corrections.

(Chronis et al., 1996; Danovaro et al., 1996). Previous S2-based SDB estimations in the same basin reached an optical depth limit of $16.5 \mathrm{~m}$ (Traganos and Reinartz, 2017a).
Related errors to the observed detection depth of the deepest $P$. oceanica bed could arise due to two factors. The first concerns the effective penetration depth of imagery which exploits information on the 

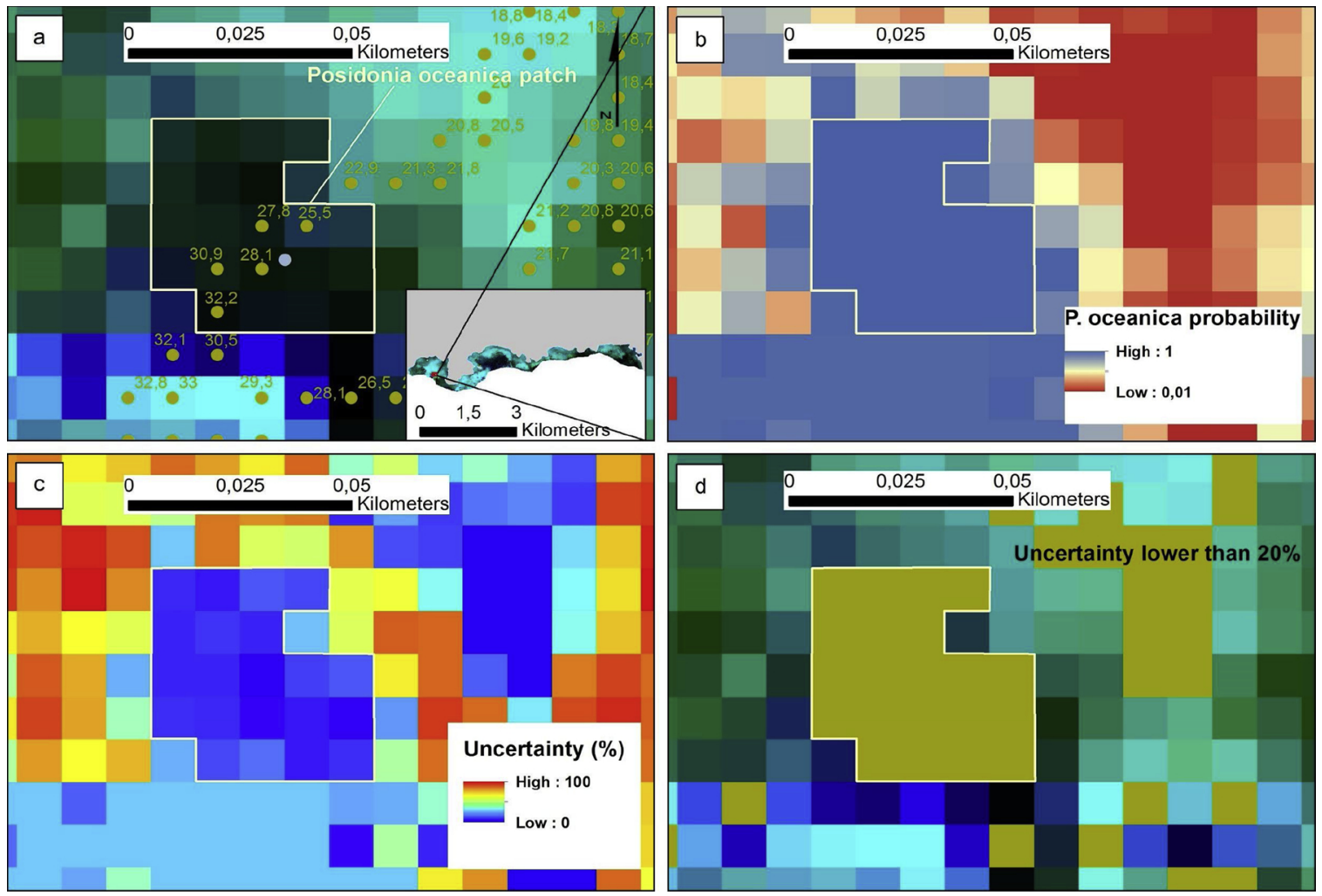

Fig. 10. Probability and uncertainty of $P$. oceanica seagrass distribution in the Samaria site (south Crete). (a) Rrs ${ }^{b}$ S2-A 3-2-1 composite with deep dense $P$. oceanica seagrass patch within yellow polygon. The light blue circle indicates the presence of $P$. oceanica seagrass as observed in situ. The golden circles depict mean depths of the in situ depth measurement points that fall within the same pixels. (b) Probability of occurrence of $P$. oceanica seagrass following SVM-derived classification. (c) General uncertainty (\%). (d) Uncertainties of $P$. oceanica seagrass distribution lower than $20 \%$ are displayed with golden polygons (For interpretation of the references to colour in this figure legend, the reader is referred to the web version of this article).

diffuse attenuation coefficient to estimate the maximum depth for which an underwater habitat could be identified by optical remote sensing. A combination of an image-based (Lyzenga, 1978, 1981) and a semi-analytical approach (Lee et al., 2000) yielded a depth penetration of S2 imagery at $30.2 \mathrm{~m}$ in $560 \mathrm{~nm}$. Therefore, the observed detection depth lies $2 \mathrm{~m}$ beyond the EPD of the green band $(560 \mathrm{~nm})$; past the EPD in $560 \mathrm{~nm}$, water column correction could possibly produce erroneous results as light would be reflected only by the water column and not by the substrate. The second factor is related to the SDB estimation using an empirical ratio-based approach. Fig. 9 indicates that the implemented SDB approach here - coastal aerosol to green ratio algorithm - saturates in depths over $22 \mathrm{~m}$ in addition to providing a RMSE of $4.31 \mathrm{~m}(\mathrm{~b} 1 / \mathrm{b} 3)$, respectively. This could produce an over-estimation of SDB due to greater water penetration in $443 \mathrm{~nm}$ in contrast to $560 \mathrm{~nm}$. The second major finding concerns the statistical advantage of forming the ratio of the b1 with the green band to derived bathymetry in comparison to the more widely implemented blue to green band ratio (Stumpf et al., 2003; Traganos and Reinartz, 2017a).

This is justified by the improved r-squared value, lower RMSE, and the smaller sensitivity of the former to variation in bottom reflectance than the latter (Fig. 9). The statistical gains of b1/b3 are clearly attributed to the greater water column penetration of b1 than b2. The errors in both ratio approaches derive from the highly steep and diverse underwater seascape morphology in Samaria. Studies on SDB (Bramante et al., 2013; Collin and Hench, 2012; Pacheco et al., 2015) have shown that sensors with coastal aerosol bands perform better in comparison to those lacking one. Further investigation in different underwater seascapes (low slopes, homogeneous seabed cover) could yield more insights into the capability of S2 for coastal SDB, the requirements on the in situ data acquisition, and the exploitation of an operational semi-automated, cloud-based method for basin- to globalscale coastal SDB (Traganos et al., 2018a, 2018b).

We summarize this section by reporting some additional sensor- and method-wise issues which could affect the accuracy of near-future applications of Sentinel-2 in coastal waters of varying water surface conditions, water column composition, depth, and seabed reflectance. First, regarding corrections, the applied atmospheric correction to derive the L2A product, Sen2cor has been designed for land-based applications and does not estimate water aerosols.

It has demonstrated, however, its efficiency in correcting the atmospheric interference over water in areas without sunglint (B. Pflug, personal communication; 06/09/2017). In the present study, two sites, 


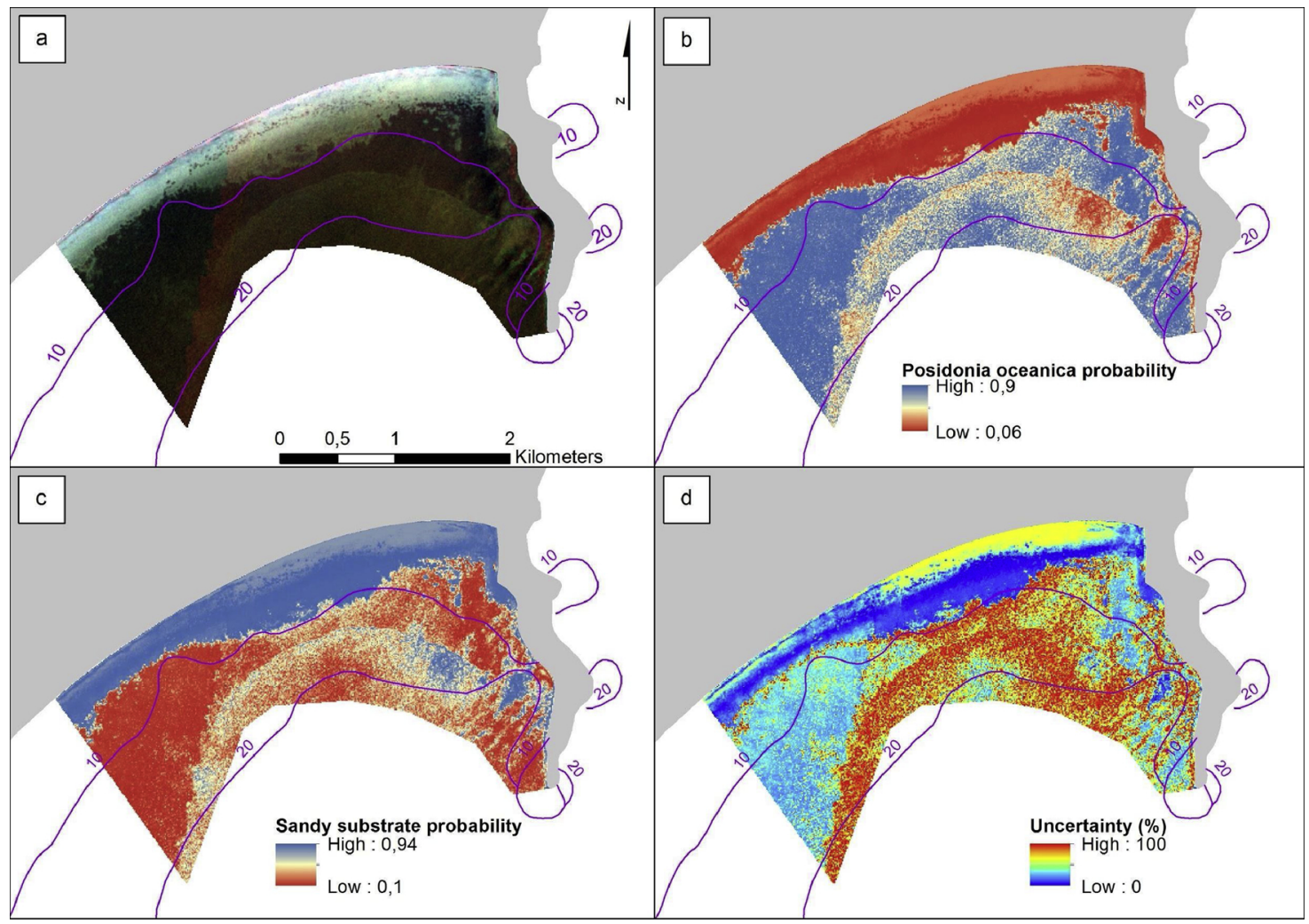

Fig. 11. Probability and uncertainty of habitat distribution in Schinias. Displayed probabilities are the most accurate results (overall accuracy) of machine learningbased classification. Bathymetric contours derived from the Hellenic Navy Hydrographic Office are displayed in purple. Masked land is displayed in grey colour. (a) Deglinted S2-A 3-2-1 composite of the survey site. (b) SVM-derived P. oceanica probability. (c) SVM-derived sandy substrate probability. (d) Uncertainty (\%) (For interpretation of the references to colour in this figure legend, the reader is referred to the web version of this article).

Schinias and Gavdos are heavily 'polluted' with sunglint (Fig. 5). Additionally, the different angle acquisitions of S2 cause granule limits to be visible (Figs. 1a, c, Figure 4 4a, b, c). This appears to be a S2-specific issue and can hinder image statistical analysis, especially in change detection studies due to the difficulty behind radiometrically-corrected composites. Moreover, the sunglint technique following Hedley et al. (2005) can over-correct very bright reflectances (e.g. shallow sands) due to the contribution of substrate NIR reflectance to the water-leaving NIR reflectance. We observe this issue in Fig. $11 \mathrm{~d}$ with higher uncertainty (yellow values) over the brighter, shallow sands. Furthermore, the utilised adjacency effect corrections of Sen2Cor perform inadequately for water surface pixels near the shoreline (Dörnhöfer et al., 2016). Adjacency effect could, therefore, produce erroneous reflectance values in both sites in the south of Crete due to their large seabed slopes. As for $15 / 10 / 2017$, there is a reported $3 \%$ error in the spectral response function of Sentinel-2 A over coastal aerosol and blue wavelengths (both in use here), which can potentially further affect reflectances in coastal water applications, wherein these bands are highly exploited (B. Pflug, personal communication; 06/09/2017). Last but not least, downscaling b1 (Brodu, 2017) enhances its resolution from
60- to 10-m/pixel; this exploits the spatial information of b1 but introduces relationships between it and the other visible bands which could possibly obstruct subsequent corrections.

Random Forests and Support Vector Machine algorithms have been used to derive the probability of occurrence of the three distinctive habitats in the protected areas, while uncertainty of each class has been calculated for each site based on Shannon index (Shannon, 1949) to unveil regions where the presented S2-A-based methodological workflow may have succeeded or failed. Both machine learning algorithms have been extensively used in image classification under several approaches (Belgiu and Dragut, 2016; Maulik and Chakraborty, 2017). The use of Shannon's entropy as a metric of uncertainty is also not common in the domain of satellite remote sensing. The two algorithms provide different accuracies in each site. In Schinias, SVM provide the highest overall accuracy (S2 file) at $87.18 \%$, with a small misclassification between the two classes. This misclassification can be possibly attributed to the mixed pixels which occur in the area between seagrass and sand. These can occur mainly in the borders of the meadow as the meadow has a compact form and few patches exit out of it or after a short storm that has transferred fine sand particles on the 


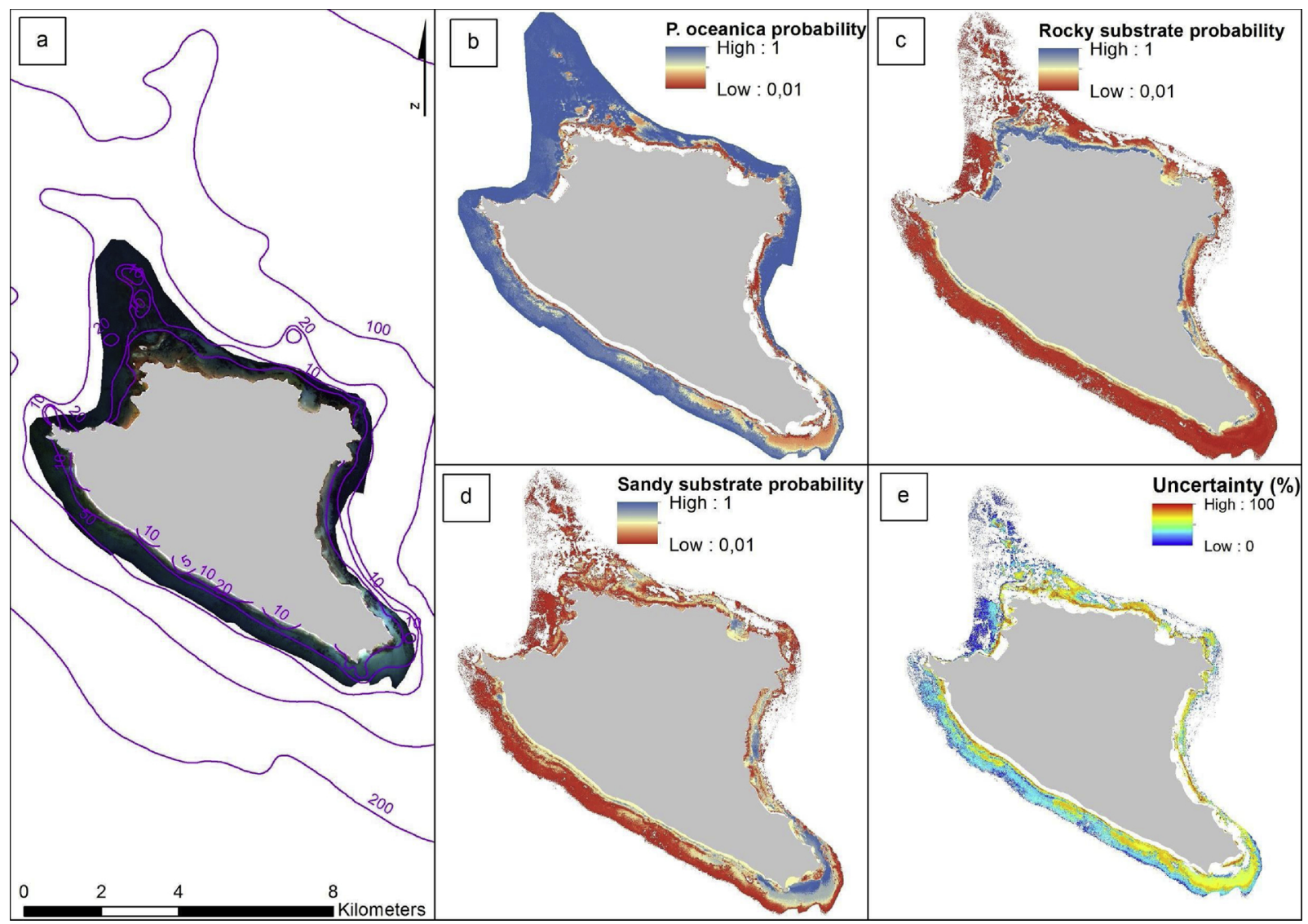

Fig. 12. Probability and uncertainty of habitat distribution in Gavdos. Displayed probabilities are the most accurate results (overall accuracy) of machine learning-based classification. Bathymetric contours derived from the Hellenic Navy Hydrographic Office are displayed in purple. Masked land is displayed in grey colour. (a) Deglinted S2-A 3-2-1 composite of the survey site. (b) RF-derived P. oceanica probability. (c) RF-derived rocky substrate probability. (d) RFderived sandy substrate probability. (e) Uncertainty (\%) (For interpretation of the references to colour in this figure legend, the reader is referred to the web version of this article).

leafs. In Gavdos, RF produces the highest accuracy of $58.18 \%$ which is somewhat poor. This is maybe due to the fact that Gavdos coastal habitats are characterized by a highly fragmented seascape where all three mentioned habitats can exist within one S2 pixel $\left(100 \mathrm{~m}^{2}\right)$. In Samaria, the highest accuracy in the classification of the seagrass class is produced from SVM classifier at $100 \%$ accuracy with an overall accuracy of $80 \%$ (S2 file). There, mixed habitats also exist in a S2 pixel while the rocky substrate is temporarily covered by sand or small grains of pebbles which amplifies spectral confusion.

The selected field data were collected from field activities and/or from the interpretation of high-resolution aerial (1-m/pixel) and satellite images (2-m/pixel). By using them in an image classification with $10-\mathrm{m} /$ pixel, we expect a mixed-pixel problem - inhomogeneity is introduced from neighboring areas which will be included in the pixel, thus a random pixel will contain spectral information from different types of cover. Per pixel level unmixing can be a solution to overcome such issues (Poursanidis et al., 2015). Another approach could be the collection of large homogeneous datasets corresponding to the same pixel size of Sentinel-2 in the form of polygons or the selection of pixels directly from the image corresponding to homogeneous areas; a comparison with high resolution imagery can support the selection of such areas. Also, the use of object-oriented analysis can be advantageous where spatial and texture information is utilized in addition to spectral information (Ma et al., 2017).

All in all, the full, open and free archive of the Sentinel-2 satellite constellation allows time- and cost-efficient, highly accurate coastal habitat mapping and satellite derived bathymetry. This new wealth of high-quality remote sensing data raises the need for suitable preprocessing, processing and analysis to extract appropriate quantitative and qualitative information. Standardizing methodologies for the two herein explored mapping efforts will enable monitoring from seasonal to decadal scales at regional to global spatial scales; this, in turn, will allow the development of spaceborne quantitative indicators for effective ecosystem management and conservation through the utilization of newly developed cloud environments (Google Earth Engine, DIAS etc). 


\section{Acknowledgements}

Dimosthenis Traganos is supported by a DLR-DAAD Research Fellowship (No. 57186656). We thank ESA for providing Sentinel-2 A data through the Sentinels Scientific Data Hub. We also thank the GlobColour project team for the provision of their excellent services based on L3 Ocean Colour products.

\section{References}

Belgiu, M., Dragut, L., 2016. Random forest in remote sensing: a review of applications and future directions. Isprs J. Photogramm. Remote Sens. 114, 24-31.

Borfecchia, F., Micheli, C., Carli, F., et al., 2013. Mapping spatial patterns of Posidonia oceanica Meadows by means of daedalus ATM airborne sensor in the coastal area of Civitavecchia (Central Tyrrhenian Sea, Italy). Remote Sens. 5, 4877-4899.

Boudouresque, C.F., Bernard, G., Bonhomme, P., Charbonnel, E., Diviacco, G., et al, 2012. Protection and Conservation of Posidonia Oceanica Meadows. RAMOGE pub, Tunis.

Bramante, James F., Raju, Durairaju Kumaran, Sin, Tsai Min, 2013. Multispectral derivation of bathymetry in Singapore's shallow, turbid waters. Int. J. Remote Sens. Vol. 34 (Iss. 6).

Breiman, L., 2001. Random forests. Mach. Learn. 45, 5-32. https://doi.org/10.1023/ A:1010933404324.

Brodu, N., 2017. Super-resolving multiresolution images with band-independent geometry of multispectral pixels. Ieee Trans. Geosci. Remote Sens. 55 (8), 4610-4617.

Chronis, G., et al., 1996. Downward fluxes. In: Tselepides, A., Papadopoulou, K.N., Polychronaki, T. (Eds.), CINCS: Pelagic-Benthic Coupling the Oligotrophic Cretan Sea, MAST-II Mediterranean Targeted Project. pp. 82-111.

Collin, A., Hench, J.L., 2012. Towards Deeper Measurements of Tropical Reefscape Structure Using the WorldView-2 Spaceborne Sensor. Remote Sens. 4, 1425-1447.

Cullen-Unsworth, L., Unsworth, R., 2013. Seagrass meadows, ecosystem services, and sustainability. Environ. Sci. Policy Sustain. Dev. 55, 14-28. https://doi.org/10.1080/ 00139157.2013 .785864

Danovaro, R., Della Croce, N., et al., 1996. Seasonal and spatial distribution of pico-,nano-, and microparticulate matter and bacterioplankton in the Eastern Mediterranean Sea. In: Tselepides, A., Papadopoulou, K.-N., Polychronaki, T. (Eds.), CINCS: Pelagic-Benthic Coupling the Oligotrophic Cretan Sea, MAST-II Mediterranean Targeted Project. pp. 69-81.

Dörnhöfer, K., Göritz, A., Gege, P., Pflug, B., Oppelt, N., 2016. Water constituents and water depth retrieval from Sentinel-2A-a first evaluation in an oligotrophic lake. Remote Sens. 8 (11), 941.

ESA, 2015. SENTINEL-2 User Handbook. pp. 64

Eugenio, F., Marcello, J., Martin, J., 2015. High-resolution maps of Bathymetry and benthic habitats in shallow-water environments using multispectral remote sensing imagery. IEEE Trans. Geosci. Remote Sens. 53 (7), 3539-3549.

Goodman, James A., Purkis, Samuel J., Phinn, Stuart R. (Eds.), 2013. Coral Reef Remote Sensing, A Guide for Mapping, Monitoring and Management. Springer, Dordrecht Heidelberg New York London ISBN 978-90-481-9291-5.

Hamana, M., Komatsu, T., 2016. Real-Time Classification of Seagrass Meadows on Flat Bottom with Bathymetric Data Measured by a Narrow Multibeam Sonar System. Remote Sens. 8, 96.

Hedley, J.D., Harborne, A.R., Mumby, P.J., 2005. Simple and robust removal of sun glint for mapping shallow-water benthos. Int. J. Remote Sens. 26 (10), 2107-2112.

Hedley, J.D., Roelfsema, C.M., et al., 2016. Remote sensing of Coral Reefs for monitoring and management: a review. Remote Sens. 8 (2), 118.

Hossain, M.S., Bujang, J.S., Zakaria, M.H., Hashim, M., 2014. The application of remote sensing to seagrass ecosystems: an overview and future research prospects. Int. J. Remote Sens. 36, 61-114.

Knudby, A.L., Nordlund, 2011. Remote sensing of seagrasses in a patchy multi-species environment. Int. J. Remote Sens. 32, 2227-2244.

Koedsin, W., Intararuang, W., Ritchie, R.J., Huete, A., 2016. An Integrated Field and Remote Sensing Method for Mapping Seagrass Species, Cover, and Biomass in Southern Thailand. Remote Sens. 8 (4), 292.

Lee, Z.P., Du, K.P., Arnone, R., 2000. A model for the diffuse attenuation coefficient of downwelling irradiance. J. Geophys. Res. 110.

Levin, N., Coll, M., Fraschetti, S., Gal, G., et al., 2014. Biodiversity data requirements for systematic conservation planning in the Mediterranean Sea. Mar. Ecol. Prog. Ser. 508, 261-281.
Lyons, M.B., Phinn, S.R., Roelfsema, C.M., 2012. Long term land cover and seagrass mapping using Landsat and object-based image analysis from 1972 to 2010 in the coastal environment of South East Queensland, Australia. ISPRS J. Photogramm. Remote Sens. 71, 34-46.

Lyzenga, D.R., 1978. Passive remote sensing techniques for mapping water depth and bottom features. Appl. Opt. 17, 379-383.

Lyzenga, D.R., 1981. Remote sensing of bottom reflectance and water attenuation parameters in shallow water using aircraft and Landsat data. Int. J. Remote Sens. 2, $71-82$.

Maritorena, S., Morel, A., Gentili, B., 1994. Diffuse reflectance of oceanic shallow waters: influence of water depth and bottom albedo. Limnol. Oceanogr. 39, 1689-1703.

Maulik, U., Chakraborty, D., 2017. Remote sensing image classification: a survey of support-vector-machine-based advanced techniques. IEEE Geosc. Remote Sens. Mag. 5, 33-52.

Mouw, C.B., Greb, S., Aurin, D., DiGiacomo, P.M., Lee, Z., Twardowski, M., Binding, C., Hu, C., Ma, R., Moore, T., Moses, W., Craig, S.E., 2015. Aquatic color radiometry remote sensing of coastal and inland waters: challenges and recommendations for future satellite missions. Remote Sens. Environ. 160, 15-30.

Pacheco, A., Horta, J., Loureiro, C., Ferreira, Ó., 2015. Retrieval of nearshore bathymetry from Landsat 8 images: a tool for coastal monitoring in shallow waters. Remote Sens. Environ. 159 (15), 102-116.

Platt, J.C., 2000. Probabilistic outputs for Support Vector Machines and comparisons to regularized likelihood methods. In: Smola, A.J. (Ed.), Advances in Large Margin Classifiers, pp. 61-74.

Poursanidis, D., Barnias, A., Lymberakis, P., 2014. Assessment of the Conservation Status of Posidonia oceanica meadows in the Samaria National Park, an MPA in Crete, Greece. Proceedings of the 5th Mediterranean Symposium on Marine Vegetation 143-148p.

Poursanidis, D., Chrysoulakis, N., Mitraka, Z., 2015. Landsat 8 vs. Landsat 5: A comparison based on urban and peri-urban land cover mapping. Int. J. Appl. Earth Obs. Geoinf. 35, 259-269.

Poursanidis, D., Topouzelis, K., Chrysoulakis, N., 2018. Mapping coastal marine habitats and delineating the deep limits of the Neptune's seagrass meadows using VHR earth observation data. Int. J. Remote Sens. 39 (23), 8670-8687.

Psarra, S., Tselepides, A., Ignatiades, L., 2000. Primary productivity in the oligotrophic Cretan Sea (NE Mediterranean): seasonal and interannual variability. Prog. Oceanogr. 46 (2-4), 187-204.

Sagawa, T., Boisnier, Etienne, Komatsu, Teruhisa, et al., 2010. Using bottom surface reflectance to map coastal marine areas: a new application method for Lyzenga's model. Int. J. Remote Sens. 31 (12), 3051-3064.

Shannon, C.E., 1948. A mathematical theory of communication. Bell Syst. Tech. J. 27 (3), $379-423$.

SoHelME, 2005. In: Papathanassiou, E., Zenetos, A. (Eds.), State of the Hellenic Marine Environment. HCMR Publ., pp. 360.

Stumpf, R.P., Holderied, K., Sinclair, M., 2003. Determination of water depth with highresolution satellite imagery over variable bottom types. Limnol. Oceanogr. 48, $547-556$.

Traganos, D., Reinartz, P., 2017a. Mapping Mediterranean seagrasses with Sentinel-2 imagery. Mar. Pollut. Bull. 134, 197-209.

Traganos, D., Reinartz, P., 2017b. Interannual change detection of Mediterranean seagrasses using RapidEye image time series. Front. Plant Sci. https://doi.org/10.3389/ fpls.2018.00096. In Press.

Traganos, D., Poursanidis, et al., 2018a. Estimating satellite-derived bathymetry (SDB) with the google earth engine and Sentinel-2. Remote Sens. 10, 859.

Traganos, D., Aggarwal, et al., 2018b. Towards global-scale seagrass mapping and monitoring using Sentinel-2 on google earth engine: the case study of the Aegean and ionian seas. Remote Sens. 10, 1227.

van der Linden, S., Rabe, A., et al., 2015. The EnMAP-Box - a toolbox and application programming interface for EnMAP data processing. Remote Sens. 7 (11), 249-311 266.

Vapnik, V., 1995. The Nature of Statistical Learning Theory. Springer-Verlag, New York, pp. 188.

Vassallo, P., Paoli, C., et al., 2013. The value of the seagrass Posidonia oceanica: a natural capital assessment. Mar. Pollut. Bull. 75, 157e167.

Waycott, M., et al., 2009. Accelerating loss of seagrasses across the globe threatens coastal ecosystems. Proc. Natl. Acad. Sci. U. S. A. 106, 12377-12381.

Wu, T.F., Lin, C.J., Weng, R.C., 2004. Probability estimates for multi-class classification by pairwise coupling. J. Mach. Learn. Res. 5, 975-1005.

Zhang, C., 2015. Applying data fusion techniques for benthic habitat mapping and monitoring in a coral reef ecosystem. Isprs J. Photogramm. Remote Sens. 104, 213-223. 